\title{
EDITORIAL
}

\section{A Importância de Construir Dados para a Medicina do Futuro}

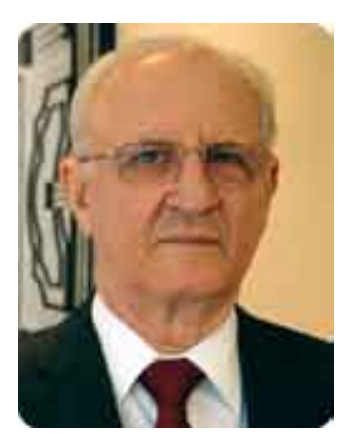

\section{The Importance of Building Data for Future Medicine}

\author{
Gilson Soares Feitosa ${ }^{1}$, José Ricardo Madureira de Almeida ${ }^{2}$ \\ ${ }^{1}$ Editor-Chefe da Revista Cientifica do Hospital Santa Izabel; ${ }^{2}$ Diretor Técnico Assistencial \\ do Hospital Santa Izabel; Salvador, Bahia, Brasil
}

No final do século XIX e início do século XX, predominavam as escolas europeias de Medicina em relação aos métodos de ensino e pesquisa.

A Medicina americana já começava a despontar com muitos valores e seguiam e aperfeiçoavam os passos das escolas europeias.

Naquele momento, quando por iniciativa da Sociedade Médica Americana, providenciou-se uma profunda revisão do ensino médico nos Estados Unidos da América (EUA), do que resultou uma adequação e qualificação das escolas de medicina. Pugnava-se por estabelecer o princípio de que nos centros universitários todos os pacientes deveriam servir de fonte de informação para construção do conhecimento médico e sua expansão.

Esse era o pensamento da Escola de Medicina da Universidade de Johns Hopkins que detinha à época os grandes valores da Medicina, notadamente William Osler, e que serviu de modelo para esse desenvolvimento.

Nos anos seguintes, tal ideia prevaleceu e, juntamente com direcionamento de recursos à investigação médica, iniciou-se a era científica da Medicina com grandes avanços desde os anos 50 .

A oportunidade de vivenciar um pouco desse momento ocorreu no Medical College da Pensilvânia, nos anos 70, onde percebia-se que não havia um único caso de cateterismo realizado que não estivesse atrelado a algum projeto de pesquisa no laboratório, por meio de estudos fisiológicos que eram conduzidos na sala, nem sempre com finalidade diagnóstica do caso em si, senão como informação para outros casos.

A constituição dos comitês de ética em pesquisa restringiu, de maneira

Correspondence addresses: Dr. Gilson Feitosa gilson-feitosa@uol.com.br

\section{Copyright}

(C) 2019 by Santa Casa de Misericórdia da Bahia. All rights reserved.

ISSN: 2526-5563 apropriada, a realização de exames que não fossem de interesse específico para o caso em questão e com o consentimento livre e esclarecido do paciente antes do início do exame.

Nos dias atuais, um novo cenário se vislumbra à frente, com o advento da informatização de dados, com volume e rapidez cada vez mais impressionantes, podendo-se neste momento já processar uma quantidade impensável de informações (Big Data) que poderão conduzir, no futuro 
próximo, a conclusões tão detalhadas que permitirão, previsivelmente, atuar de uma maneira personalizada no cuidado do paciente.

Isto é, enquanto no momento aplicamos ao indivíduo os recursos disponíveis que trazem vantagens para um grupo com algumas características parecidas com as suas, em um futuro próximo deveremos estar aptos a escolher a forma de tratamento melhor aplicável às suas condições demográficas, psicossociais, fisiológicas, fisiopatológicas, circadianas, dentre outros aspectos, como individualmente determinado por um conjunto enorme de dados que permitam esta especificação, tais quais: idade, sexo, peso, altura, raça, ritmo de atividade física, intestinal, urinária, tipo de roupa, temperatura frequentada, e milhares de características individuais de constituição genética e de interação com alimentos ou medicações de uso concomitante, e de forma órgão ou tecido seletiva.

Estudos como esse já estão em curso!

$\mathrm{O}$ que nos remete àquela consideração inicial de que cada caso virá a ser de interesse coletivo, contribuindo para essa enorme colcha de retalhos de informações. E com isso a necessidade de que se providenciem informações detalhadas, precisas, consistentes, em hospitais, ambulatórios/consultórios, de atendimento primário a terciário, a alimentar esse Big Data, tarefa nada simples a ser implementada, porém necessária para atender esta necessidade de um futuro não muito distante.

Mais um importante desafio para a Medicina contemporânea entre tantos outros que temos tido que enfrentar e haveremos de vencer.

\section{Referências}

1. Duffy TD. Historical perspectives in medical rducation. The Flexner Report - 100 Years Later Yale Journal of Biology and Medicine. 2011;84:269-76.

2. Mhoney MM, Asch SM. Humanwide: A comprehensive data base for precision health in primary care. Ann Fam Med $-2019 ; 17: 273$. 